\title{
Analysis of asymmetric temperature fields for the duct-ventilated embankment of highway in permafrost regions
}

(1)

(a. State Key Laboratory of Frozen Soil Engineering, Cold and Arid Regions Environmental and Engineering Research Institute, Chinese Academy of Sciences, Lanzhou 730000; b. Sichuan Communication Surveying \& Design Institute, Chengdu 610017)

\section{ABSTRACT:}

The heat capacity and polythermal effect of highway roadbeds with wide asphalt pavements have become increasingly significant, which causes their influences on engineering and permafrost issues to become prominent. A duct-ventilated embankment is a potential mean to proactively cool ground temperatures. This method is applied experimentally in a highway for the first time. According to a field testing in the Tibetan Plateau Highway Pilot Project, a duct-ventilated embankment has excellent cooling effect. The mean annual ground temperature reduction at the embankment/natural ground surface interface is $1.62{ }^{\circ} \mathrm{C}$. The mean annual temperature difference between the south- and north-facing slopes reaches $2.39{ }^{\circ} \mathrm{C}$. This difference results in the asymmetry of the underlying temperature field and longitudinal roadbed cracking. The asymmetric distribution of the duct-ventilated embankment temperature field is caused by differential sun exposure and the heat transfer process and intensity within the duct. Differential sun exposure is a major factor between the south- and north-facing sides, accounting for $84 \%$, whereas the remaining $16 \%$ is ascribed to the different heat transfer processes within the duct. The amount of asymmetry is increased to $20 \%$ by the duct and slightly accentuated by the ventilation duct. To avoid this effect, future projects should focus on solving problems related to roadbed direction and the effect of slope temperature difference on ground temperature. Measures are recommended to be taken to regulate both slope temperature adjustment 
and ventilation ducts, and thus, effectively combine the advantages of both measures in embankment design.

Keywords: permafrost; wide highway subgrade; duct ventilation; asymmetry

\section{Introduction}

Heat transfer between the land and the atmosphere in permafrost regions is a major factor that influences the geothermal field through surface thermal boundary condition. A considerable temperature difference may form between the south- and north-facing slopes after embankment construction (Zhang et al., 2011). The mean annual temperature of shallow strata in the south-facing slope can be over $3{ }^{\circ} \mathrm{C}$ higher than that in the north-facing slope. Such difference forms an asymmetrical distribution of the temperature field in the underlying soil layer of the embankment, which results in certain potential hazards, such as the non-uniform lateral deformation of the embankment (Sheng et al., 2005). A survey conducted on the roadbed cracking defects of the Qinghai-Tibet Highway (Dai et al., 2006) presents the following results.

1) Longitudinal cracking of the roadbed in permafrost regions is closely related to solar radiation.

2) The number of longitudinal cracks on the south-facing side of the roadbed accounts for $78 \%$ of the total number of cracks, whereas the total length of longitudinal cracks on this side of the roadbed accounts for over $75 \%$ of the total crack length.

3) Longitudinal cracking is the most severe damage on road sections along the north-south direction. 
4) Longitudinal cracking of the roadbed is the second most prevalent type of roadbed defects, ranking below roadbed subsidence.

The major influencing factors of longitudinal cracking are roadbed direction and embankment height, solar radiation, and wind veloctiy and direction (Dou et al., 2002; Li, 2001). To minimize or eliminate the influences of these factors, a geotextile has been laid on highways in permafrost regions in Alaska, USA to enhance the mechanical stability of the roadbed (Savage, 1991). Meanwhile, related measures, such as the application of duct-ventilated embankment, crushed-rock revetment, sunshields, and heat pipes, have been used to maintain roadbed stability by adjusting the temperature fields of embankment slopes, embankments, or roadbeds (Niu et al., 2003; Sun et al., 2006; Yu et al., 2005, 2007a; Hayley et al., 1983; Lepage et al., 2010).

A duct-ventilated embankment is an engineering technique that uses ventilation ducts buried horizontally at a certain depth within an embankment to connect with the atmosphere. Ventilation ducts are typically perpendicular to the subgrade direction. Thus, permafrost temperature below the embankment can be adjusted via convective heat transfer between ducts and soil. Some studies on this approach via indoor physical model tests, in situ engineering tests, and numerical simulations have been conducted in the Qinghai-Tibet Railway. The results of these studies indicate the following findings: 1) Enhancing the thermal stability of a roadbed by using a duct-ventilated embankment is technically feasible (Niu et al., 2002; Yu et al., 2002; Lai et al., 2004). 2) Various factors, such as the diameter of the ventilation duct, buried depth, and duct spacing, considerably influence the cooling effect 
of duct-ventilated embankment (Niu et al., 2006a, 2006b; Li et al., 2005). Effective cooling can be achieved under certain circumstances, such as a large duct diameter and shallow buried depth of ventilation ducts. In addition, the lateral asymmetry of the temperature field of the lower soil layer can be improved. 3) Small ventilation duct spacing improves cooling effect. Given that the main source of heat absorption for an embankment with a gravel road surface originates from the slope, temperatures at the two sides of the embankment remains distributed in an asymmetrical manner (Niu et al., 2008). With the planning and development of highway construction in western China, the increased width of high-grade asphalt highways will inevitably increase the risk of severe hazards because of stronger permafrost degradation compared with that in current highways. Previous research was mostly conducted using the Qinghai-Tibet Railway as the basis. However, essential differences exist in boundary conditions, heat transfer processes, and heat transfer strengths between roads and railways (Yu et al., 2006). An investigation of heat transfer processes in a duct-ventilated embankment (Yu et al., 2007b) showed that the mean annual heat release per meter of roadbeds at $0.5 \mathrm{~m}$ below the ventilation duct was $469 \mathrm{~J} /(\mathrm{m} \cdot \mathrm{h})$ for gravel pavements, whereas the heat release for asphalt pavements was only $96 \mathrm{~J} /(\mathrm{m} \cdot \mathrm{h})$. Considering climate warming and inappropriate design, current engineering measures are likely to be ineffective for asphalt pavements. For a wide, high-grade asphalt highway, the convective heat transfer efficiency of a ventilation duct will be reduced to a certain degree because of the increase in heat absorption at the roadbed center. In addition, the increased length of a ventilation duct further aggravates the problems in the use of such structures in wide, high-grade asphalt pavements. Based on practical engineering applications, this study describes the analyses of the following 
issues: (1) the cooling effect of a duct-ventilated embankment under strong endothermic conditions; (2) the influence of increased subgrade width on embankment thermal boundary conditions, ventilation duct temperature change, airflow characteristics, and ground temperature distribution features; and (3) the engineering problems arising from such influences. Researching and analyzing these issues are of critical for effective decision making and for prioritizing research related to highway construction in permafrost regions in China.

\section{Test field and observations}

The duct-ventilated embankment for the test road of the Chinese Academy of Sciences (CAS) was completed in August 2009. This road is located at the Beilu River Experiment Base of the State Key Laboratory of Frozen Soils Engineering (SKLFSE)-Cold and Arid Regions Environmental and Engineering Research Institute (CAREERI), CAS (3449’N, 92 $\left.54^{\circ} \mathrm{E}\right)$, in the open area between the Qinghai-Tibet Highway (K3056+500) and the Qinghai-Tibet Railway. The mean annual air temperature is $-3.8{ }^{\circ} \mathrm{C}$. The freezing and thawing indices are $2131{ }^{\circ} \mathrm{C}$. $\mathrm{d}$ and $903{ }^{\circ} \mathrm{C}$. d, respectively. The mean annual wind veloctiy is $4.1 \mathrm{~m} / \mathrm{s}$. The prevalent wind direction is northwest. Geographical features include the south Beilu River Basin and piedmont alluvial highland plains. The highland meadow area is relatively flat with a slight topographic relief and a vegetation coverage of 70\%-90\%. Soil sampling shows that the moisture content of the test subgrade seasonal active layer is approximately $18 \%$. The permafrost table is approximately $2.0 \mathrm{~m}$. A $1.0-5.0 \mathrm{~m}$ soil-bearing ice layer is present near the permafrost table. The ice volume is over $80 \%$. The surface is covered by a $20-30 \mathrm{~cm}$ layer of 
114 thick highland vegetation, with mostly silty sand and silty clay at a depth of $10 \mathrm{~m}$ below the

115 surface. The layer below this layer mainly consists of intensely weathered reddish brown mudstone. The mean annual ground temperature ranges from $-1.0{ }^{\circ} \mathrm{C}$ to $-0.5{ }^{\circ} \mathrm{C}$. The test result is highly representative because the area is located in a typical permafrost region with a high ice volume and warm ground temperature on the Qinghai-Tibet Plateau.

The test roadbed is directed $20^{\circ}$ north of east, with clearly defined south- and north-facing sides as shown in Fig. 1 (The south-facing side is located on the left of the embankment when facing the direction of Lhasa, whereas the north-facing side is located on the right). The distance from the center of the ventilation ducts to the natural ground in the embankment is $120 \mathrm{~cm}$. The ventilation ducts are open-ended, and their diameter is $40 \mathrm{~cm}$. Temperature probes were arranged at the center and on the wall of the ventilation ducts, the roadbed center, the left and right shoulders, and the left and right slope bases. The spacing between temperature measuring points in the ventilation ducts is $4.0 \mathrm{~m}$ and $3.0 \mathrm{~m}$ from both ends of (within $5.0 \mathrm{~m}$ below the surface of the earth or pavement) and $1 \mathrm{~m}$ in deep parts (more than $5.0 \mathrm{~m}$ below the surface). Boundary temperature probes were arranged at the embankment $1.0 \mathrm{~m}$ on the pavement and the north-facing side. The spacing of the thermistor temperature probes deployed on the embankment/natural ground surface interface is $1.0 \mathrm{~m}$. Thermistor temperature probes, which were manufactured by SKLFSE-CAREERI of CAS, were used for 


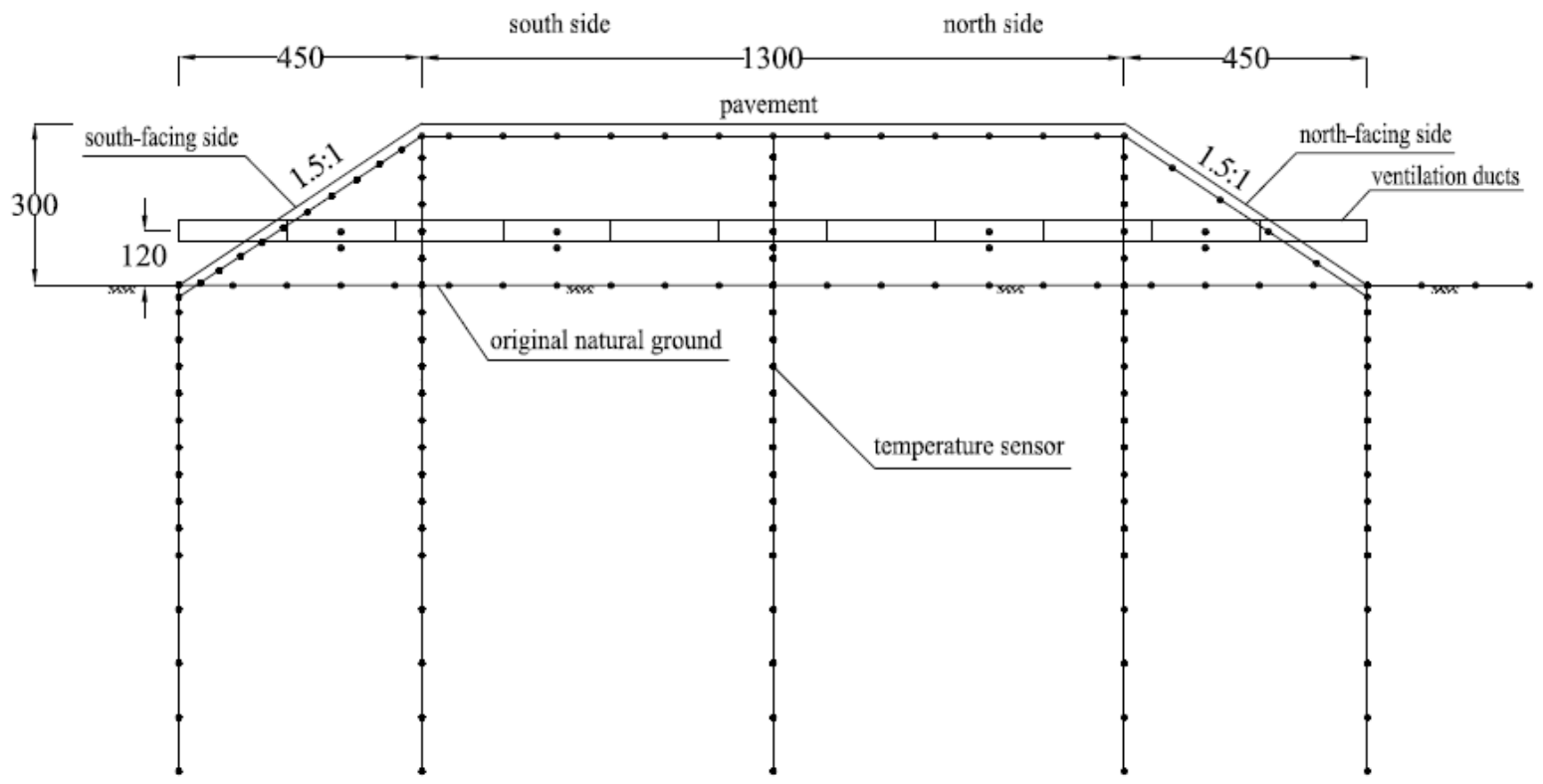

Fig. 1. Diagram of the test roadbed design and the roadbed temperature observation system (unit: $\mathrm{cm}$ ).

\section{Analysis of shallow surface temperature at embankment boundaries}

A change in embankment surface temperature directly influences or may even control the internal soil temperature field of the roadbed and the change in the underlying permafrost temperature. In addition to air temperature, solar radiation governs the changes in surface temperature of the embankment. Fig. 2 shows the mean annual temperature distribution in shallow layers $(0.5 \mathrm{~m})$ around the embankment from September 2009 to January 2011. As shown in the figure, the embankment boundary temperature is distributed asymmetrically. The mean annual temperature at $50 \mathrm{~cm}$ below the entire asphalt pavement was $3.33{ }^{\circ} \mathrm{C}$. The highest pavement temperatures were observed near the road center. The highest temperature reached 
than the mean annual air temperature. The natural surface temperature and the mean annual air temperature were $-0.50{ }^{\circ} \mathrm{C}$ and $-3.80{ }^{\circ} \mathrm{C}$, respectively. The mean annual temperature of the north-facing slope was $0.07{ }^{\circ} \mathrm{C}$, whereas that of the south-facing slope was $2.46{ }^{\circ} \mathrm{C}$. The mean annual temperature difference between the south- and north-facing slopes was, on average, $2.39{ }^{\circ} \mathrm{C}$. Under the effect of the strong heat absorption of the pavement, the embankment surface temperature of the high-grade highway reached $2.36{ }^{\circ} \mathrm{C}$. This temperature is higher than the surface temperature of the Qinghai-Tibet Railway $\left(0.59{ }^{\circ} \mathrm{C}\right)$. Considering its width, the roadbed would have greater effect on the thermal response of the subgrade than that of the typical and narrower Qinghai-Tibet Railway embankment. The thermal state of the wide, high-grade pavement embankment boundary would result in a difference in the temperature of the underlying permafrost and heat transfer intensity compared with those of the Qinghai-Tibet Railway and the Qinghai-Tibet Highway. The wide, high-grade pavement would exert a more negative effect on the overall temperature field of the underlying soil layer than the typical and narrower embankments of the Qinghai-Tibet Railway and Highway. Moreover, the distinct differences in the thermal state of the south- and north-facing slopes of the embankment would lead to asymmetrical temperature fields. The increase in the asymmetrical distribution of the embankment boundary temperature would cause thaw settlements and compaction deformations of the ice-rich permafrost. Such phenomena would ultimately result in longitudinal embankment cracks. Therefore, adjusting slope temperature is of critical in designing embankments that is part of engineering. 


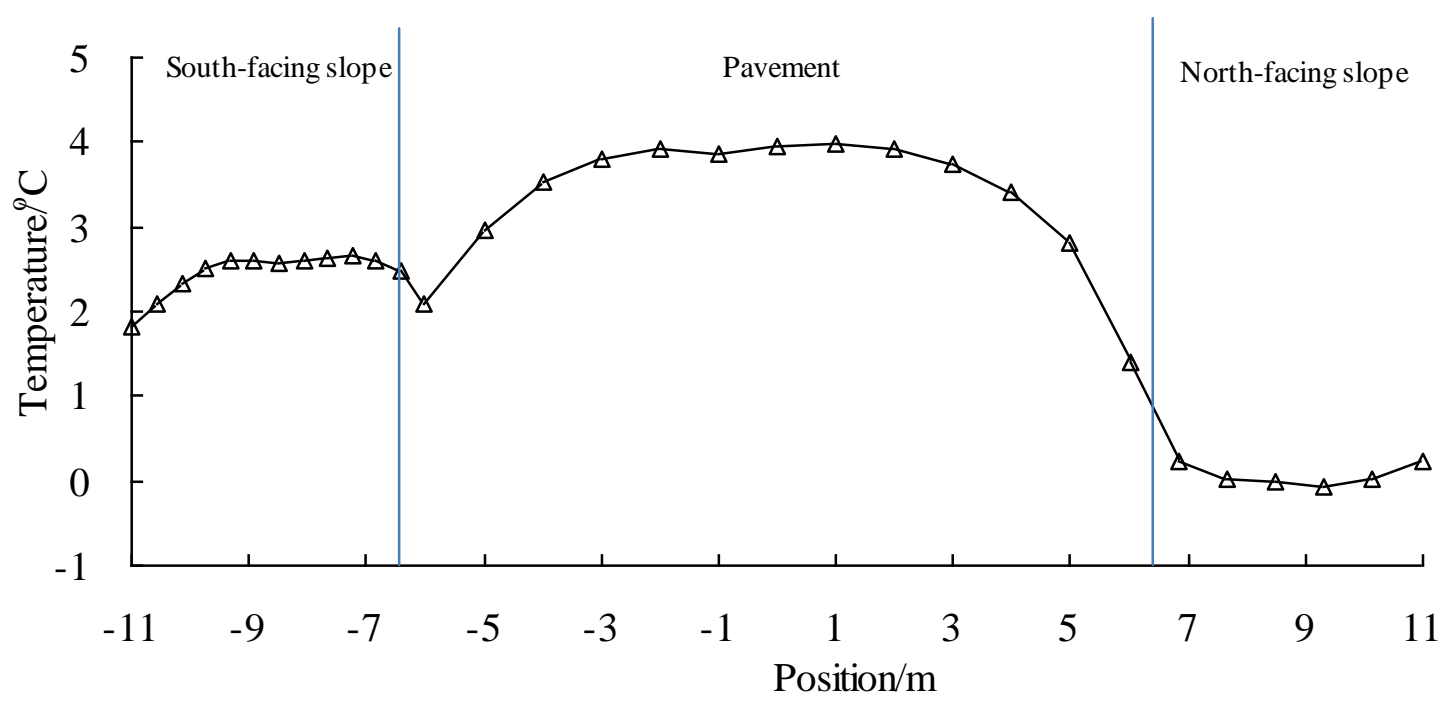

171

Fig. 2. Mean annual temperature distribution at a depth of $0.5 \mathrm{~m}$ of the embankment surface.

Fig. 3 shows the mean annual temperature along the embankment/natural ground interface for the reference and duct-ventilated embankments. As shown in Fig. 3, a clear difference in the embankment/natural ground interface can be observed when a duct-ventilated embankment is used. The thermal effect on roadbed was greater for the asphalt pavement. The heat from the asphalt pavement was reduced by duct ventilations when duct adjustment measures were undertaken. The mean annual ground temperature at the embankment/natural ground surface interface was $-0.42{ }^{\circ} \mathrm{C}$ for the duct-ventilated embankment and $1.20{ }^{\circ} \mathrm{C}$ for the reference embankment. The evident temperature decrease indicates that this engineering measure exhibits a cooling effect on the wide, high-grade pavement. However, asymmetrical ground temperature distribution occurred in the embankment/natural ground interface for both the reference and duct-ventilated embankments. The average temperature in the north and south sides of the reference embankment was $0.72{ }^{\circ} \mathrm{C}$ and $1.65{ }^{\circ} \mathrm{C}$, respectively. The average temperature difference between the north and south lanes was $0.93{ }^{\circ} \mathrm{C}$. This value could be 
used to define the amount of asymmetry present in the reference embankment. The average temperature in the north and south sides of the duct-ventilated embankment was $-0.98{ }^{\circ} \mathrm{C}$ and $0.13{ }^{\circ} \mathrm{C}$, respectively. The average temperature difference between the north and south lanes was $1.11^{\circ} \mathrm{C}$. Duct ventilation contributed to decreasing temperature in the north side by an additional $0.18{ }^{\circ} \mathrm{C}$. Consequently, the amount of asymmetry increased by $20 \%$. This additional temperature reduction corresponds to $16 \%$ of the overall difference in temperature between the south and north sides. The remaining $84 \%$ is attributed to the difference in differential sun exposure, which is considered the same in both the reference and duct-ventilated embankments.

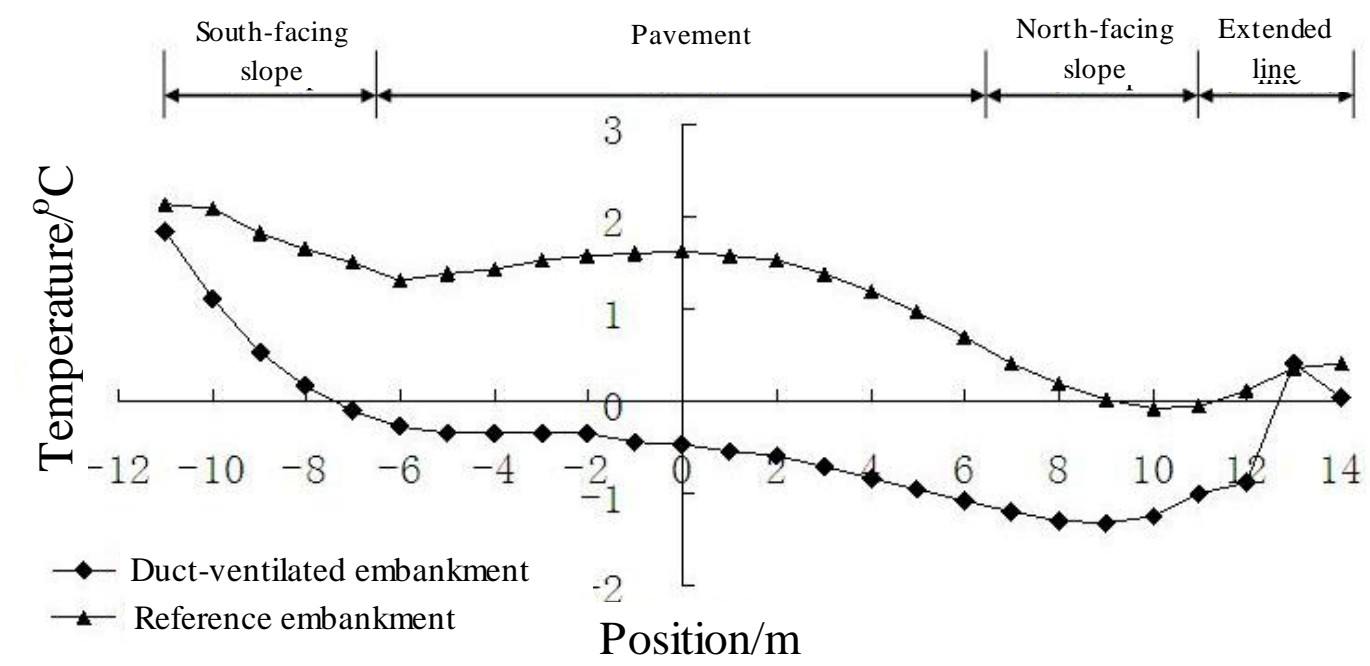

Fig. 3. Mean annual temperature along the embankment/natural ground interface for the reference and duct-ventilated embankments.

\section{Temperature analysis of air within a duct}

For the duct-ventilated embankment, the temperature change in the underlying permafrost is mainly influenced by the thermal boundary condition of the ventilation duct and the embankment, as well as the embankment fill between ducts. Therefore, the analyses of the 
duct center and wall temperature are highly significant for the heat transfer process and cooling efficiency of this engineering measure. Fig. 4 shows the mean annual duct air temperature and duct wall temperature. Observations indicate that the temperature of the duct wall is greater than the air temperature in the duct, which provides the basic conditions for the heat transfer process between the duct wall and the air in the duct wall. Consequently, heat was extracted along the entire length of the duct. The average temperature difference between the duct wall and the air in the duct in the south and north lanes was $0.21{ }^{\circ} \mathrm{C}$ and $0.28{ }^{\circ} \mathrm{C}$, respectively. The heat transfer process between the duct and the embankment in the north lane was stronger than that in the south lane. The heat in the subgrade was transferred to the air in the duct and caused air temperature to rise rapidly. This phenomenon resulted in differences in the heat transfer process and intensity and exacerbated the asymmetry of the temperature field of the duct-ventilated roadbed to a certain extent.

Although sun exposure has been confirmed to produce an asymmetrical thermal field in the reference embankment, such thermal field was further accentuated by the ventilation duct. The amount of asymmetry increased to 0.2 times compared with that of the reference embankment. Consequently, the ventilation duct would contribute to the asymmetry of the thermal field as a result of different heat transfer processes between the north and the south lanes. Given that the strength of the permafrost soil is strongly related to the ground temperature, such asymmetry will lead to a difference in the roadbed freezing-and-thawing response and the deformation process. The duct-ventilated embankment test conducted by CAS shows that asymmetry is the cause of cracks emerging in the embankment after only 1 year after completion. The number of cracks increased after 2 years. 


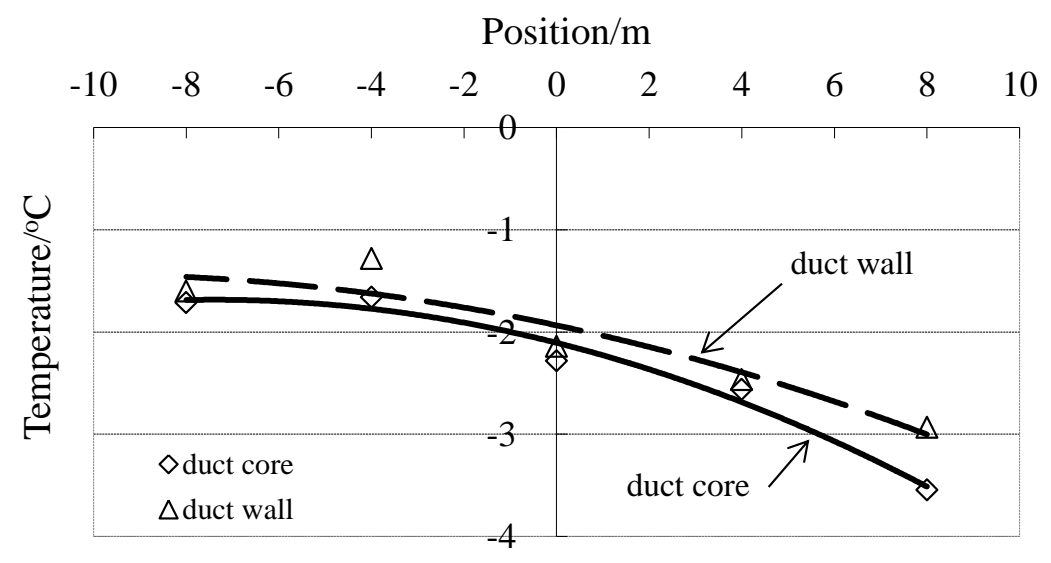

Fig. 4. Mean annual duct air temperature and duct wall temperature.

\section{Character of airflow within a duct}

An understanding of the forced convection within a duct is highly significant to the design and theoretic calculation of cooling effect in a duct-ventilated embankment. With an accuracy of $\pm 0.2 \mathrm{~m} / \mathrm{s}$, hot wire wind-velocity sensors (STF20, China) were used to measure air velocity in a duct. The positive value in Fig. 5 represents airflow from the south side to the north side of the embankment, whereas the negative value represents airflow from the north side to the south side. As shown in Fig. 5, the annual average airflow velocity is approximately $1.61 \mathrm{~m} / \mathrm{s}$. Velocities ranged from $0-4.30 \mathrm{~m} / \mathrm{s}$ during winter and reached a peak of $4.79 \mathrm{~m} / \mathrm{s}$ in January. Airflow velocities ranged from 0-2.00 m/s during summer. For $79.5 \%$ of a year, air flowed from the north side to the south side of the embankment. Both the difference in airflow velocity between winter and summer and airflow direction coincide with the duct temperature distribution shown in Fig. 4. This phenomenon explains why mean annual air temperature is low at the north side and high at the south side.

Given the difference between wall temperature and air temperature, the latter will change by convective heat transfer when air flows into the ventilated duct. Heat transfer can be 
calculated from the temperature change between the inlet and outlet of the ventilation duct as follows: $Q=c . m . \Delta t, \quad$ where $m$ is the mass and $m=\rho . \mathrm{V}=\rho . \mathrm{A} . \mathrm{v}, c$ is the isobaric heat capacity and $c=1.005 \mathrm{KJ} /(\mathrm{kg} . \mathrm{K}), v$ is the mean annual rate for the fitting (unit: $\mathrm{m} / \mathrm{s}$ ), $A$ is the

cross-sectional area of the ventilation duct (unit: $\mathrm{m}^{2}$ ), and $\Delta t$ is the mean annual temperature difference between the inlet and outlet of the ventilation duct (unit: ${ }^{\circ} \mathrm{C}$ ). The calculations show that the average heat convection within the duct is approximately $4.42 \times 10^{10} \mathrm{~J} / \mathrm{m}^{2}$. In addition, the duct provides unidirectional heat release.

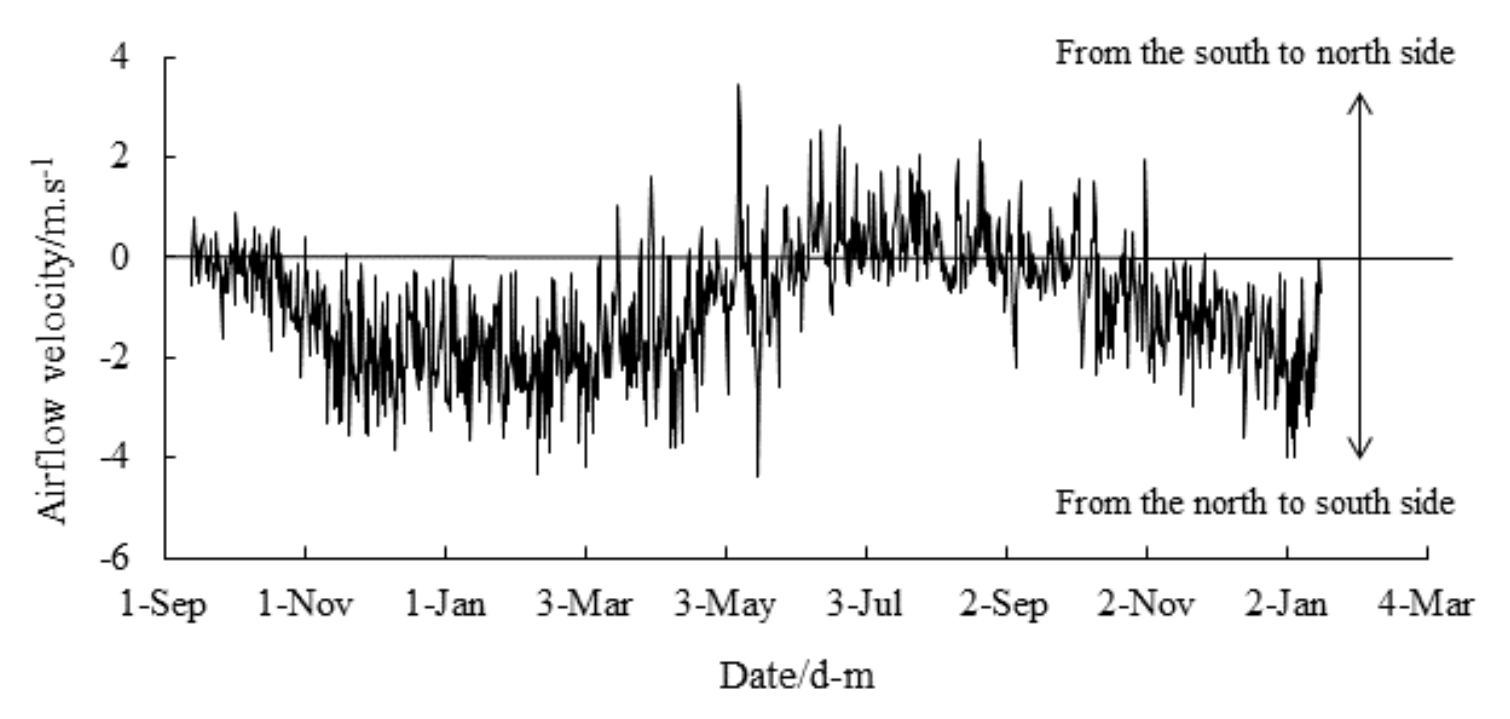

Fig. 5. Changes in airflow velocity within the ventilation duct from September 2009 to January 2011.

\section{Asymmetry of the roadbed temperature field}

Fig. 6 shows the roadbed ground temperature distribution on September 30, 2011. As a typical ground temperature cross section, it reflects the influence of the warm season on the roadbed ground temperature field, its changing trends, and the heat transfer processes. As shown in the figure, the temperature field is symmetrically distributed around the center of the roadbed within the embankment. The ground temperature isolines are parallel to the road surface. That 
is, the ground temperature gradient is vertical to the embankment. Consequently, heat is transferred down from the embankment surface with the pavement as the heat source. The isotherms on the south side of the roadway appear at slightly greater depths than at the center and north side. The warm permafrost $\left(-1^{\circ} \mathrm{C}-0{ }^{\circ} \mathrm{C}\right)$ is approximately $5.5 \mathrm{~m}$ thick on the south slope and approximately $2.5 \mathrm{~m}$ on the north slope. These findings reflect the influence of heat transfer during the warm season and the heat absorption of the south slope on the roadbed temperature field. The ventilation ducts confines the $6{ }^{\circ} \mathrm{C}$ and $7{ }^{\circ} \mathrm{C}$ isotherms to the upper portion of the roadbed, which indicates that the ventilation ducts can reduce soil temperature during warm seasons. However, the temperatures at the bottom $10 \mathrm{~cm}$ of the ventilation duct and at the center between the ventilation ducts differ by approximately $0.5{ }^{\circ} \mathrm{C}$. The heat absorbed by the pavement and the slope surfaces can be transferred to the roadbed from the soil between the ducts.

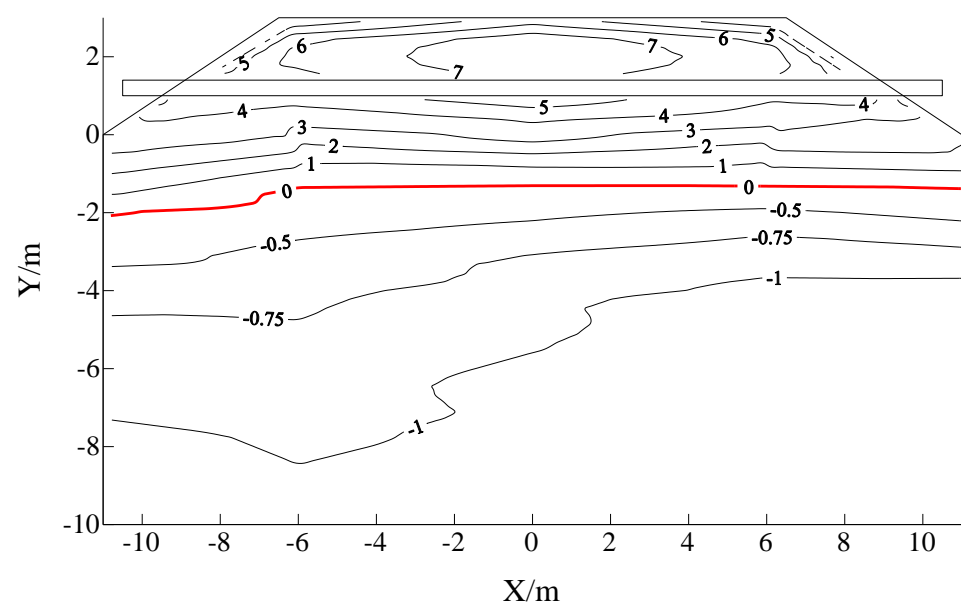

Fig. 6. Roadbed ground temperature cross section during the warm season (September 30, 2011).

Fig. 7 shows the roadbed ground temperature distribution on March 30, 2012. The figure reflects the influence of the entire winter season on the roadbed ground temperature field of the underlying permafrost, as well as its change trends and processes. According to the 
temperature distribution, the asymmetry of the roadbed temperature field is most evident around the roadbed center where temperatures at the north side are lower than that at the south side. Such asymmetry gradually increases from the north-facing slope to the south-facing slope. The temperature difference at the bottom of the ducts in the left and right shoulders is 4 ${ }^{\circ} \mathrm{C}$ within the embankment. The temperature difference at coordinates $(-10,-8)$ and $(+10,-8)$ does not exceed $0.5^{\circ} \mathrm{C}$. The asymmetry of the temperature field is evident. According to the temperature and airflow characteristics of the ventilation ducts, the air within the duct flows from the north-facing slope to the south-facing slope during winter. Roadbed temperature asymmetry during cold seasons is closely related to airflow velocity and direction within the duct.

The preceding analysis shows that the ventilation duct profoundly affects subgrade temperatures. The heat convection of the dominant wind from the north side to the south side in the ducts intensifies their temperature differences to a certain extent. However, most of the asymmetrical distribution of the temperature field in the wide, duct-ventilated embankment is attributed to differences in sun exposure. In future engineering design, engineering problems caused by sun exposure and ventilation duct should therefore be considered. Measures are recommended to be taken to regulate both slope adjustment and ventilation ducts, which effectively combine the advantages of both measures in an embankment design. 


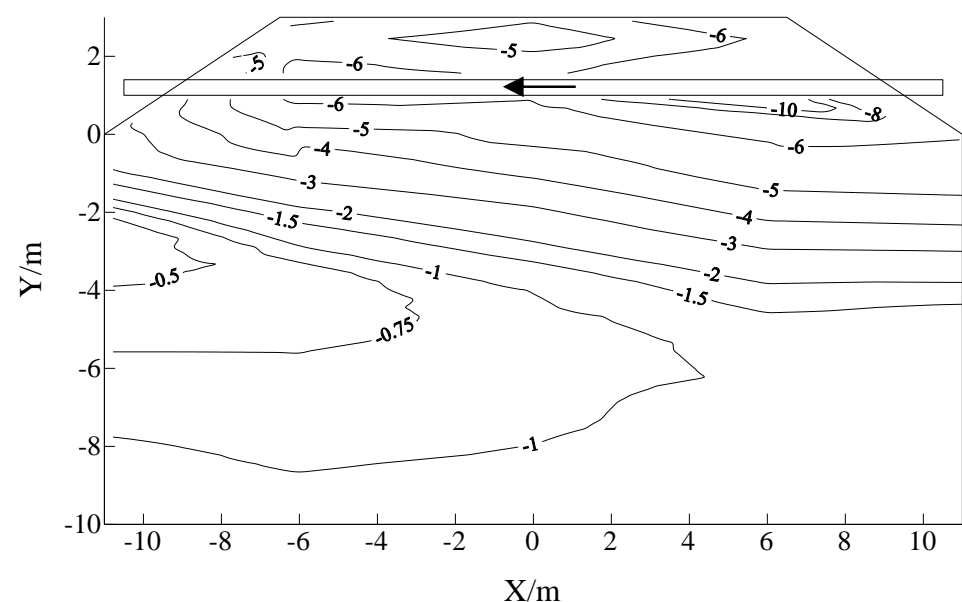

Fig. 7. Roadbed ground temperature cross-section during the cold season (arrow indicates prevailing wind direction) (March 30, 2012).

Roadbed temperature field asymmetry is caused by differences in sun exposure and ventilation ducts. This finding is further proven in observations of the duct-ventilated embankment temperature fields conducted by the CAS. Fig. 6 shows the roadbed ground temperature distribution 2 years after project completion. During the warmest time of the year, the $0{ }^{\circ} \mathrm{C}$ isotherm is mostly parallel to the embankment/natural ground interface, whereas the $-1{ }^{\circ} \mathrm{C}$ isotherm is asymmetrical. The depth of the $-1.0{ }^{\circ} \mathrm{C}$ isotherm or the lower limit of the warm permafrost differs by approximately $3 \mathrm{~m}$ between the south and north portions of the subgrade. Temperature change in the permafrost leads to a change in its mechanical properties. The warm permafrost layers at the left and right shoulders of the roadbed, which differ in terms of both temperature and thickness, undergo thaw settlements and compaction deformations of different degrees. Such differences in deformation cause longitudinal cracks to appear on the embankment only one year after the end of construction; the cracks increase to $2 \mathrm{~cm}$ in width after 2 years (Fig. 8). These longitudinal cracks are located at the center of the south lane, and in accordance with the temperature field distribution. 


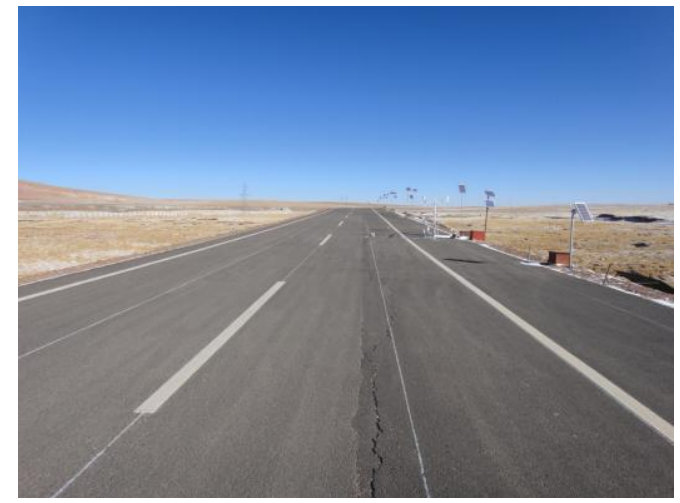

Fig. 8. Longitudinal cracks began to appear on the embankment only one year after the completion of

construction.

\section{Conclusions}

The use of duct-ventilated embankments for highways is considered an important measure to proactively reducing ground temperatures. The highway exhibited excellent cooling effect based on the test. However, an asymmetrical temperature field could be observed. The conclusions are summarized as follows.

1) For a wide pavement, the embankment boundary temperature field was highly asymmetrical. The average temperature $50 \mathrm{~cm}$ below the asphalt pavement reached $3.33{ }^{\circ} \mathrm{C}$ and influenced the temperature field of the underlying permafrost. The average temperature differences between the south- and north-facing slopes resulted in the asymmetry of the underlying temperature field.

2) The asymmetrical distribution of the duct-ventilated embankment temperature field was attributed to differential sun exposure and the heat transfer process and intensity within the duct. Differential sun exposure was a major factor and accounted for $84 \%$ of this asymmetry. The remaining $16 \%$ was attributed to the different heat transfer processes within the duct. The 
amount of asymmetry was raised to $20 \%$ by the duct.

3) The prevailing wind that moved along the direction from the north side to the south side in the ducts resulted in lower air temperature at the north side than at the south side. This phenomenon slightly enhanced the asymmetry of the roadbed temperature field along the ducts.

4) The temperature differences caused by the difference in sun exposure and the heat transfer in the ducts produced an asymmetric distribution of the roadbed temperature field. The asymmetry of the permafrost changed its mechanical characteristics and resulted in different thaw settlements and deformations in the warm permafrost with varying temperatures and thicknesses on the north and south roadbed shoulders. In addition, it produced longitudinal cracks on the embankment.

\section{Acknowledgements}

This research was supported the National Science and Technology Support Program (No. 2014BAG05B03), the National Key Basic Research and Development Plan (No. 2012CB026106), the National Science Foundation for Fostering Talents in Basic Research of the National Natural Science Foundation of China (No. 41121061), the Open Project of State Key Laboratory of Frozen Soil Engineering (No. SKLFSE201211), and Chinese Postdoctoral Science Foundation (No. 2012M521819). At the same time, I would like to extend my sincere gratitude to the professor Liu Yong-zhi, researcher Zhang Jian-ming, and personnel of the State Key Laboratory of Permafrost Engineering and the Tibetan Plateau Research Base. Finally, I want to sincerely thank the work the reviewers and editors put into improving my 
manuscript.

\section{References}

Dai, H. S., Sheng, Y., Cheng, J., 2006. Longitudinal Cracks diseases and Occurrence regularity of Qinghai-Tibet highway. Highway, (1), 85-88. (in Chinese)

Dou, M. J., Hu, C. S., He, Z.W., Zhang, Y. Q., 2002. Distributing Regularities of Subgrade Diseases in Permafrost Section of the Qinghai-Tibetan Highway. Journal of glaciology and geocryology, (6),

Hayley, D. W., Roggensack, W. D., Jubien, W. E., Johnson, P. V., 1983. Stabilization of sinkholes on the Hudson Bay Railway. Proceedings of 4th International Conference on Permafrost . Washington, DC, 468-473.

Lai, Y. M., Wang, Q. S., Niu, F. J., Zhang, K. H., 2004. Three-dimensional nonlinear analysis for temperature characteristic of ventilated roadbed in permafrost regions. Cold Regions Science and Technology, 38(2), 165-184.

Lepage, M. J., Doré, G., Fortier, D., Murchison, P., 2010. Thermal Performance of the Permafrost

Li, N., Su, B., Quan, X. J., Li, G. Y., 2005. Approach on temperature field analysis and design principle of Protection Techniques at Beaver Creek Experimental Road Site, Yukon, Canada. In 10th

Li, Z. L., 2001. Diseases mechanism of subgrade and pavement of Qinghai-Tibet Highway. Highway, (8), 105-109. (in Chinese) 

geocryology, 28(3), 380-389. (in Chinese)

Niu, F. J., Cheng, G. D., Lai, Y. M., 2002. Laboratory study on ventilation duct roadbed of Qinghai-Tibet railway . Journal of Xi'an engineering university , 24(3), 1-6. (in Chinese)

Niu, F. J., Ma, W., Lai, Y. M., 2003. Priliminary analysis on emgineering effect of ventilation embankment

Yu, Q.H., Pan, X. C., Cheng G.D., He, N. W., 2007a. Experimental study on the cooling process of shading 
Yu, Q. H., Pan, X. C., Cheng, G. D., He, N. W., 2007b. Study on main influential factors on ventilated embankment and corresponding measures. Chinese Journal of Rock Mechanics and Engineering, 26(sup.1), 3045-3051. (in Chinese)

Yu, Q.H., Cheng, G.D., He, N.W., Pan, X. C., 2006. Research on heat transfer process of roadbed in permafrost regions in the condition of different road surface and width. Progress in Natural Science, 16 (11), 1482-1486 (in Chinese). Experiment of the Ventilated Railway Embankment in Permafrost Regions. Journal of glaciology and geocryology 24(5), 601-607. (in Chinese)

Yu, Q., Shi, C., Niu, F., He, N., Roth, K., 2005. Analysis of temperature controlled ventilated embankment. Cold Regions Science and Technology, 42(1), 17-24.

412 Science and Technology, 65(2), 226-233. 